\title{
Keberhasilan Early Goal-Directed Therapy dan Faktor Pengganggu pada Pasien Sepsis Berat di Instalasi Gawat Darurat Rumah Sakit Dr. Hasan Sadikin Bandung yang Akan Menjalani Pembedahan
}

\author{
Mira Silviana, Doddy Tavianto, Rudi Kurniadi Kadarsah \\ Departemen Anestesiologi dan Terapi Intensif \\ Fakultas Kedokteran Universitas Padjadjaran/Rumah Sakit Dr. Hasan Sadikin Bandung
}

\begin{abstract}
Abstrak
Early goal directed therapy (EGDT) bertujuan menurunkan morbiditas dan mortalitas pada pasien sepsis berat dan syok sepsis namun pelaksanaannya sering menemukan kendala. Tujuan penelitian ini mengevaluasi keberhasilan EGDT pada pasien sepsis berat di Instalasi Gawat Darurat (IGD) Rumah Sakit Dr. Hasan Sadikin Bandung yang menjalani pembedahan serta mencari faktor-faktor yang memengaruhi keberhasilan EGDT. Penelitian dilakukan dengan metode deskriptif observasional pada bulan Juni-Agustus 2014 dengan subjek penelitian pasien IGD berusia $>14$ tahun dalam kondisi sepsis berat yang menjalani pembedahan. Keberhasilan EGDT ditentukan berdasar atas pedoman surviving sepsis campaign. Hasil penelitian dari 30 pasien didapatkan 27 pasien berhasil dilakukan EGDT, sedangkan 3 pasien meninggal. Faktor yang memengaruhi EGDT, yaitu faktor medis, kecepatan dalam mendiagnosis sepsis berat, lama pemeriksaan penunjang, faktor koagulasi yang memanjang, dan faktor nonmedis, yaitu lamanya keputusan keluarga, prosedur pengurusan administrasi, dan ketersediaan alat. Simpulan, keberhasilan EGDT di Rumah Sakit Dr. Hasan Sadikin dengan faktor medis dan nonmedis sebagai faktor pengganggu yang berperan dalam keberhasilan pelaksanaannya.
\end{abstract}

Kata kunci: Early goal directed therapy (EGDT), pembedahan, sepsis berat

\section{The Success of Early Goal-Directed Therapy and its Confounding Factors in Patients with Severe Sepsis Admitted to the Emergency Room of Dr. Hasan Sadikin General Hospital for Surgery}

\begin{abstract}
Early goal-directed therapy (EGDT) is conducted to reduce morbidity and mortality in patients with severe sepsis and septic shock. The purpose of this study was to evaluate the success of EGDT in patients with severe sepsis in the emergency room (ER) of Dr. Hasan Sadikin General Hospital Bandung who were going to undergo surgery and the factors that contributed to the success of EGDT. This study was a descriptive observational study that took place in June-August 2014. Subjects were ER patients, aged over 14 years old, who came with severe sepsis condition and were going to undergo surgery. The successful EGDT in this study was determined according to the surviving sepsis campaign (SSC) guideline such as a central venous pressure of 8-12 $\mathrm{mmHg}$, mean arterial pressure of $>65 \mathrm{mmHg}$, and central venous saturation of $>70 \%$. In this study, from 30 patients, 27 patients successfully underwent EGDT and the remaining 3 patients did not survive. Factors that affect the implementation of EGDT were divided into two factors: medical and non-medical factors. Medical factors were time needed to diagnose patient with severe sepsis, delay in laboratory findings, and abnormality of coagulation factors. The non-medical factors were family consent, procedures related to health insurance, and the availability of central venous catheter. In conclusions, EGDT is successfully achieved in $90 \%$ patients with severe sepsis in Dr. Hasan Sadikin General Hospital Bandung. Factors that contribute to the successful achievement of EGDT include medical and non-medical factors.
\end{abstract}

Key words: Early goal directed therapy, surgery, severe sepsis

Korespondensi: Mira Silviana, dr., SpAn, Departemen Anestesiologi dan Terapi Intensif Fakultas Kedokteran Universitas Padjadjaran/Rumah Sakit Dr. Hasan Sadikin Bandung, Kompl. Pertamina Walang Baru Blok N-3 RT. 009/rw 015 PlumpangJakartaUtara14260,Jl.H.Kurdi IINo.7 Moh.Toha.Bandung40243,Mobile081318704737,Emaiilmira.silviana@gmail.com 


\section{Pendahuluan}

Early goal directed therapy (EGDT) merupakan suatu tindakan resusitasi untuk memperbaiki kondisi pasien dalam keadaan sepsis berat atau syok septik. Early goal directed therapy diperkenalkan pertama kali oleh Rivers dkk. ${ }^{1}$ pada tahun 2001 yang dilaksanakan dalam waktu 6 jam berhasil meningkatkan harapan hidup dan juga menurunkan angka kematian setelah hari ke-28 sebanyak 16\%. Resusitasi EGDT juga dapat menstabilkan hemodinamik pasien dengan pemberian obat-obatan, cairan, antibiotik, mengontrol derajat infeksi sehingga mengurangi kerusakan organ-organ vital lebih lanjut, dan menurunkan angka kematian pada pasien.

Sepsis berat didefinisikan sebagai suatu keadaan sepsis yang disertai disfungsi organ atau juga hipoperfusi jaringan, sedangkan syok septik merupakan sepsis berat disertai dengan hipotensi yang tidak berespons dengan pemberian cairan. Sepsis berat dan juga syok septik merupakan masalah kesehatan utama dan berhubungan dengan peningkatan angka kejadian morbiditas dan juga mortalitas pada pasien yang akan menjalani pembedahan. ${ }^{2}$

Insidensi lebih dari 1.665.000 kasus sepsis yang terjadi di Amerika Serikat setiap tahunnya dengan angka kematian 20-50\%, meningkat lebih dari $50 \%$ pada pasien yang mengalami sakit berat. ${ }^{3}$ Sepsis berat sering terjadi pada usia tua, penurunan sistem imunitas, pasien kritis, dan juga merupakan penyebab kematian utama di Intensive Care Unit (ICU). ${ }^{4}$

Anestesia memegang peranan yang penting dalam merawat pasien sepsis kritis di Instalasi Gawat Darurat (IGD), kamar operasi, ataupun di ICU. Pasien dengan trauma atau bedah risiko tinggi yang disertai dengan sepsis, optimalisasi hemodinamik sebelum terjadi suatu kegagalan organ menurunkan angka kematian $23 \%$ bila dibanding dengan pasien yang mendapatkan optimalisasi hemodinamik setelah munculnya gagal organ. ${ }^{4}$

Pada perjalanan sepsis diperoleh sirkulasi abnormal yang berupa penurunan volume intravaskular, vasodilatasi perifer, depresi miokardium, serta peningkatan metabolisme dan juga terjadi ketidakseimbangan antara pengiriman oksigen sistemik dan kebutuhan oksigen yang menyebabkan hipoksia jaringan secara global ataupun syok. Resusitasi EGDT yang dilakukan dalam penelitian Rivers dkk. ${ }^{1}$ selama 6 jam pertama berhasil meningkatkan angka harapan hidup dan juga menurunkan kematian.

Kompleksitas literatur tentang sepsis dan juga dampak potensial yang terjadi pada perawatan kesehatan pasien, mendorong para klinisi untuk membuat pedoman pengelolaan pasien sepsis sehingga membentuk surviving sepsis campaign (SSC). Pada tahun 2004 SSC menerbitkan pedoman internasional pertama untuk penanganan sepsis berat dan juga syok septik. $^{5,6}$

Pasien dengan sepsis berat atau syok septik yang datang ke Instalasi Gawat Darurat (IGD) sering kali terlambat terdiagnosis disebabkan harus menunggu pemeriksaan laboratorium/ kurangnya sumber daya manusia sehingga pasien terlambat diidentifikasi. Tindakan agresif harus segera dilakukan ketika sepsis teridentifikasi awal di IGD dengan pelaksanaan resusitasi EGDT yang secara signifikan dapat menurunkan angka kematian. ${ }^{7}$

Pasien yang telah didiagnosis sepsis berat dan syok septik memerlukan pemasangan kateter vena sentral (central venous catheterCVC). Kateter vena sentral dapat digunakan untuk memberikan infus cairan intravena, terapi infus produk darah, dan dapat pula dipergunakan untuk memonitor hemodinamik dengan memastikan tekanan vena sentral (central venous pressure-CVP) dan juga saturasi oksihemoglobin vena sentral $\left(\mathrm{ScvO}_{2}\right) .{ }^{2}$

Tujuan penelitian ini adalah mengetahui keberhasilan resusitasi EGDT terhadap pasien sepsis berat di IGD yang akan menjalani pembedahan dalam 6 jam pertama setelah CVC terpasang dan mengetahui faktor-faktor yang menghambat atau mengganggu pencapaian terapi sepsis berat pada resusitasi EGDT.

\section{Subjek dan Metode}

Penelitian menggunakan metode deskriptif observasional ini dilakukan setelah mendapat 
persetujuan/izin dari Komite Etik Penelitian Kesehatan Fakultas Kedokteran Universitas Padjadjaran/Rumah Sakit Dr. Hasan Sadikin (RSHS) Bandung. Penelitian telah berlangsung pada bulan Juni sampai dengan Agustus 2014 dengan subjek penelitian pasien IGD berusia di atas 14 tahun dalam kondisi sepsis berat yang akan menjalani pembedahan. Jumlah pasien didapatkan sebanyak 30 orang yang dilakukan prosedur EGDT sebelum dilakukan operasi. Informed consent dilakukan terhadap keluarga pasien yang akan dipasang CVC, Sebelum pelaksanaan EGDT, dilakukan pengukuran tanda vital pasien seperti tekanan darah (sistol dan juga diastol), mean arterial pressure (MAP) awal, laju nadi, suhu tubuh, saturasi oksigen, CVP awal terbaca sesaat setelah dilakukan pemasangan kateter vena sentral, urin yang keluar, serta pemeriksaan laboratorium laktat, analisis gas darah arteri, dan vena sentral.

Pada penelitian ini dilakukan pencatatan waktu kedatangan ke IGD, waktu ditetapkan pasien dalam keadaan sepsis berat, serta mengamati waktu pemasangan CVC dan juga waktu pelaksanaan EGDT selama 6 jam sesuai dengan pedoman resusitasi tanpa melakukan intervensi terhadap pasien. Keberhasilan resusitasi EGDT dapat dinilai dengan melihat kriteria resusitasi dilihat dari alur EGDT sesuai alur penanganan sepsis berat menurut Rivers dkk. dan juga menurut pedoman manajemen SSC yaitu tekanan vena sentral 8-12 mmHg, mean arterial pressure (MAP) $\geq 65 \mathrm{mmHg}$, dan $\mathrm{ScvO}_{2}>70 \%$ ditambah dengan nilai keluaran urin dan laktat.

Data dianalisis secara deskriptif disajikan dalam ukuran jumlah, rata-rata, simpangan baku, median, dan juga persentase untuk data kategori. Analisis data dari penelitian ini menggunakan program statistical product and service solution (SPSS) for windows versi 20.0.

\section{Hasil}

Penelitian telah dilakukan terhadap 30 pasien terdiri atas 15 laki-laki dan 15 perempuan, sebanyak 10 responden berusia 51-60 tahun. Penyebab terbanyak pasien sepsis berat yang

\section{Tabel 1 Karakteristik Umum Pasien}

\begin{tabular}{lc}
\hline \multicolumn{1}{c}{ Karakteristik Pasien } & Jumlah \\
\hline Jenis kelamin & \\
Laki-laki & 15 \\
Perempuan & 15 \\
Usia (tahun) & \\
$14-20$ & - \\
$21-30$ & 4 \\
$31-40$ & 4 \\
$41-50$ & 7 \\
$51-60$ & 10 \\
$61-70$ & 3 \\
$>70$ & 2 \\
Penyebab digestif & \\
Ulkus peptikum & 9 \\
Perforasi tumor & 5 \\
Perforasi gaster & 3 \\
Perforasi apendiks & 2 \\
Penyebab nondigestif & \\
Urologi & 6 \\
Ortopedi & 5 \\
\hline
\end{tabular}

datang ke IGD untuk dilakukan pembedahan adalah karena keluhan pada daerah abdomen (digestif) sebanyak 19 dengan ulkus peptikum merupakan penyebab terbanyak yaitu 9 pasien (Tabel 1).

Karakteristik hemodinamik awal pasien untuk tekanan darah sistol, diastol, dan juga MAP rata-rata masih dalam batas normal tetapi terjadi peningkatan pada laju nadi dan temperatur tubuh. Nilai awal untuk CVP dan urin rata-rata rendah. Nilai laktat rata-rata terjadi peningkatan (Tabel 2).

Semua pasien sepsis berat yang menjalani pembedahan akan dilakukan EGDT, mayoritas memberikan respons baik dengan pemberian cairan kristaloid, tiga pasien diberikan support norepinefrin, sedangkan untuk transfusi darah apakah itu PRC ataupun FFP dilakukan pada tujuh pasien. Sebelum dilakukan EGDT, pasien dilakukan pemasangan kateter vena sentral (CVC). Waktu pemasangan CVC kurang dari 3 


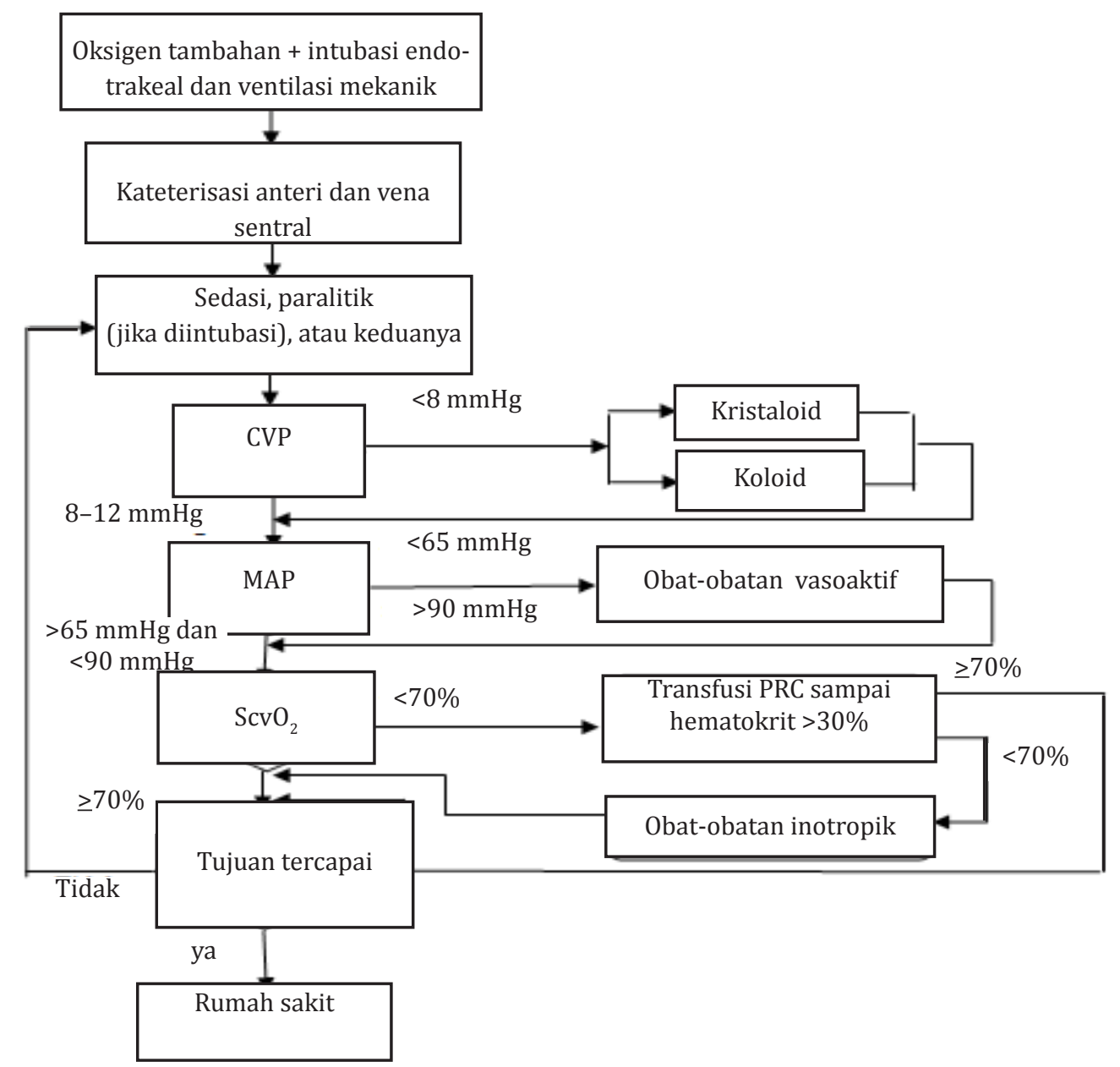

\section{Gambar Alur EGDT}

Dikutip dari: Dellinger dkk. ${ }^{2}$

jam terdapat pada 13 pasien (Tabel 3).

Pelaksanaan resusitasi EGDT telah berhasil dilakukan pada 27 pasien dan tidak berhasil pada tiga pasien. Sebanyak 16 pasien dilakukan pemasangan CVP kurang dari tiga jam dan 11 pasien dilakukan pemasangan CVP lebih dari 3 jam (Tabel 4).

Permulaan pemasangan CVC adalah 3 jam 57 menit \pm 3 jam 17 menit rata-rata, dengan pemasangan CVC tercepat adalah 30 menit dan terlama adalah 16 jam. Masa pelaksanaan EGDT didapatkan 3 jam 38 menit \pm 58 menit, dengan pelaksanaan tercepat 2 jam 48 menit dan terlama 5 jam 30 menit (Tabel 5).

Mean arterial pressure (MAP) rata-rata mengalami peningkatan tiap jam pelaksanaan EGDT dengan rata-rata 79,5-86 $\mathrm{mmHg}$. Mean arterial pressure terendah $63 \mathrm{mmHg}$ dan tertinggi $113 \mathrm{mmHg}$. Pengukuran CVP didapatkan hasil rata-rata adalah 4,7-9,1 mmHg dengan nilai CVP terendah $4 \mathrm{mmHg}$ dan tertinggi $14 \mathrm{mmHg}$. Keluaran urin ratarata juga terjadi peningkatan $32,17 \mathrm{cc} / \mathrm{jam}-71$ cc/jam serta keluaran urin terendah adalah 10 cc/jam dan tertinggi $150 \mathrm{cc} /$ jam (Tabel 6).

Pengamatan $\mathrm{ScvO}_{2}$ pada pasien sepsis berat yang dilakukan EGDT mengalami perbaikan. Nilai awal sebelum EGDT terendah 61,7\% dan tertinggi 92,4\%, setelah dilakukan EGDT jumlah pasien dengan nilai $\mathrm{ScvO}_{2} \geq 70-80 \%$ mengalami peningkatan menjadi 23 pasien, dengan nilai $\mathrm{ScvO}_{2}$ terendah $72,2, \%$ dan tertinggi $82,2 \%$. Pemeriksaan awal kadar laktat didapatkan semua pasien sebanyak 30 pasien dengan nilai laktat di atas $1 \mathrm{mmoL} / \mathrm{L}$. Nilai awal laktat terendah 1,3 $\mathrm{mmoL} / \mathrm{L}$ dan 
Tabel 2 Hemodinamik dan Laboratorium Sebelum Pelaksanaan EGDT

\begin{tabular}{lcc}
\hline \multicolumn{1}{c}{ Karakteristik } & Mean (SD) & Median (Range) \\
\hline Tekanan darah awal (mmHg) & & \\
$\quad$ Tekanan sistol & $106,2(22,19)$ & $102(62-160)$ \\
Tekanan diastol & $68,7(15,98)$ & $70(40-100)$ \\
MAP awal (mmHg) & $79,53(17,49)$ & $78(42-92)$ \\
Laju nadi (x/menit) & $114,53(12,80)$ & $114(86-138)$ \\
Temperatur tubuh $\left({ }^{\circ} \mathrm{C}\right)$ & $37,49(0,65)$ & $37,45(35,9-38,6)$ \\
$\mathrm{CVP}(\mathrm{mmHg})$ & $4,7(1,49)$ & $5(2-7)$ \\
Urine awal $(\mathrm{mL})$ & $32,17(12,57)$ & $30(15-60)$ \\
$\mathrm{SaO}_{2}(\%)$ & $96,71(2,03)$ & $97,25(92,9-99,1)$ \\
$\mathrm{ScvO}_{2}(\%)$ & $78,43(7,95)$ & $78,55(61,7-92,4)$ \\
$\mathrm{Laktat}^{(\mathrm{mmoL} / \mathrm{L})}$ & $2,81(1,47)$ & $2,35(1,3-7)$ \\
\hline
\end{tabular}

tertinggi $7 \mathrm{mmoL} / \mathrm{L}$. Setelah dilakukan EGDT didapatkan jumlah pasien dengan nilai laktat $>1 \mathrm{mmoL} / \mathrm{L}$ sebanyak 19 pasien dan nilai $<1$ $\mathrm{mmol} / \mathrm{L}$ sebanyak 8 pasien. Nilai akhir laktat terendah $0,3 \mathrm{mmol} / \mathrm{L}$ dan nilai laktat tertinggi $5 \mathrm{mmol} / \mathrm{L}$ (Tabel 7).

\section{Pembahasan}

Pelaksanaan strategi EGDT adalah tindakan resusitasi awal yang dilakukan pada pasien sepsis berat dengan tindakan resusitasi yang bersifat agresif pada 6 jam pertama terbukti dapat meningkatkan penghantaran oksigen ke jaringan. ${ }^{1}$ Pada pelaksanaan EGDT dilakukan pemberian resusitasi cairan, transfusi produk darah, penggunaan obat (vasoaktif inotropik) dengan pengukuran MAP, keluaran urin, dilakukan pemasangan kateter vena sentral untuk pengukuran CVP, dan juga pemeriksaan $\mathrm{ScvO}_{2}$ untuk menilai keseimbangan antara pengiriman oksigen sistemik dan kebutuhan oksigen. ${ }^{1}$ Keseimbangan hasil resusitasi ini ditandai dengan normalnya nilai $\mathrm{ScvO}_{2}$ serta konsentrasi laktat. $^{2}$

Tabel 3 Waktu Pemasangan CVC

\begin{tabular}{lc}
\hline Pemasangan CVC & Jumlah Pasien \\
\hline$\leq 3$ jam & 13 \\
$>3$ jam & 17 \\
\hline Jumlah & 30 \\
\hline
\end{tabular}

Berdasarkan data-data pasien sepsis berat yang datang ke IGD Bagian Bedah Rumah Sakit Dr. Hasan Sadikin Bandung, didapatkan 30 pasien yang terdiri atas 15 pasien lakilaki dan 15 pasien perempuan, didapatkan kelompok pasien terbanyak pada usia 51-60 tahun dikarenakan pada usia ini sudah terjadi penurunan fisiologi tubuh sekitar 20-30\% dan pada usia ini merupakan usia produktif. Penyebab terbanyak adalah kasus bedah digestif sebanyak 19 pasien dengan penyebab terbanyak adalah perforasi ulkus peptikum dan perforasi tumor kolon. Resusitasi EGDT berhasil dilakukan pada 27 pasien dan tidak berhasil pada tiga pasien karena meninggal sebelum EGDT berhasil dilaksanakan. Faktorfaktor yang menyebabkan kematian pada pasien tersebut disebabkan pasien dalam usia $>50$ tahun dengan sepsis berat yang disertai gangguan pada respirasi.

Pada pasien sepsis berat dengan hipoksia jaringan, terjadinya gangguan sistem respirasi akan memperberat hipoksia jaringan tersebut yang mengakibatkan disfungsi multiorgan

Tabel 4 Waktu Pemasangan CVC pada Pasien yang Berhasil Dilakukan EGDT

\begin{tabular}{lc}
\hline Pemasangan CVC & Jumlah Pasien \\
\hline$\leq 3$ jam & 16 \\
$>3$ jam & 11 \\
\hline Jumlah & 27 \\
\hline
\end{tabular}


Tabel 5 Hasil Analisis Mula Pemasangan CVC dan Lama Pelaksanaan EGDT

\begin{tabular}{lll}
\hline \multicolumn{1}{c}{ Pengamatan } & \multicolumn{1}{c}{ Mean (SD) } & \multicolumn{1}{c}{ Median (Range) } \\
\hline Mula pemasangan CVC (jam) & 3 jam 57 menit ( 3 jam 17 menit) & 3 jam 2 menit (30 menit-16 jam) \\
Masa pelaksanaan EGDT (jam) & 3 jam 38 menit (58 menit) & 3,5 jam (2 jam 48 menit-5,5 jam) \\
\hline
\end{tabular}

akan terjadi lebih cepat., ${ }^{8,9}$ Secara umum, pasien dengan keluhan lebih dari 24 jam mengalami peningkatan mortalitas sebesar 7-8 kali serta risiko komplikasi tiga kali lebih besar dibanding dengan pasien yang berobat kurang dari 24 jam. ${ }^{6}$ Pada umumnya, keterlambatan pasien disebabkan keluarga yang terlalu lama membuat keputusan untuk membawa pasien ke rumah sakit. ${ }^{7}$

Mula pemasangan CVC yang paling lambat pada penelitian ini adalah 16 jam. Faktor yang menjadi penyebab keterlambatan pemasangan CVC adalah faktor medis dan juga nonmedis. Faktor medis yang sangat memengaruhi antara lain adalah kecepatan melakukan diagnosis sepsis berat saat pasien datang ke Instalasi Gawat Darurat (IGD), lamanya waktu yang dibutuhkan untuk pemeriksaan penunjang misalnya pemeriksaan ultrasonography (USG) dan juga rontgen abdomen untuk menegakkan diagnosis, juga pemanjangan faktor koagulasi.

Faktor nonmedis yang dapat menyebabkan keterlambatan dalam pemasangan CVC adalah lamanya pihak keluarga dalam memberikan keputusan untuk dilakukan pemasangan CVC, keterbatasan sumber daya tenaga medis, prosedur pengurusan jaminan kesehatan sebelum pemasangan CVC, serta ketersediaan alat CVC di rumah sakit.

Pelaksanaan EGDT memiliki tujuan untuk memperbaiki penghantaran oksigen (delivery oxygen) ke jaringan. Masa pelaksanaan ratarata EGDT didapatkan 3 jam 38 menit \pm 58 menit dengan pelaksanaan EGDT yang paling

Tabel 6 Hemodinamik, Nilai CVP, dan Keluran Urin Pasien Selama Dilakukan EGDT

\begin{tabular}{lcccccc}
\hline Variabel & Jam & N & Mean & SD & Minimum & Maksimum \\
\hline MAP & 1 & 30 & 82,2 & 14,41 & 63 & 113 \\
& 2 & 30 & 83,8 & 11,07 & 67 & 106 \\
& 3 & 30 & 86,2 & 9,85 & 70 & 103 \\
& 4 & 29 & 89,6 & 9,85 & 73 & 112 \\
CVP & 5 & 27 & 86,9 & 8,06 & 75 & 105 \\
& 6 & 27 & 86,9 & 10,31 & 73 & 113 \\
& 1 & 30 & 6,43 & 1,30 & 4 & 8 \\
& 2 & 30 & 7,73 & 1,66 & 5 & 12 \\
Keluaran & 3 & 80 & 8,53 & 1,99 & 4 & 13 \\
Urin & 3 & 9,33 & 1,91 & 7 & 13 \\
& 4 & 27 & 9,37 & 2,01 & 5 & 14 \\
& 5 & 27 & 10,15 & 2,07 & 8 & 13 \\
& 6 & 30 & 45,17 & 19,23 & 20 & 90 \\
& 1 & 30 & 58,17 & 27,99 & 20 & 140 \\
& 2 & 30 & 65,17 & 25,88 & 20 & 150 \\
& 3 & 29 & 69,83 & 25,88 & 20 & 150 \\
& 4 & 70,93 & 22,39 & 10 & 100 \\
& 5 & 27 & 79,81 & 31,58 & 20 & 150 \\
\hline
\end{tabular}


Tabel 7 Nilai $\mathrm{ScvO}_{2}$ dan Laktat

\begin{tabular}{|c|c|c|c|c|c|}
\hline \multirow{2}{*}{$\begin{array}{c}\text { Pemeriksaan } \\
\text { EGDT }\end{array}$} & \multicolumn{3}{|c|}{ Nilai ScvO $_{2}$} & \multicolumn{2}{|c|}{ Nilai Laktat } \\
\hline & $<70 \%$ & $\geq 70-80 \%$ & $>\mathbf{8 0} \%$ & $>1 \mathrm{mmoL} / \mathrm{L}$ & $\leq 1 \mathrm{mmoL} / \mathrm{L}$ \\
\hline Sebelum (jumlah pasien) & 12 & 11 & 7 & 30 & 0 \\
\hline Setelah (jumlah pasien) & 0 & 23 & 4 & 19 & 8 \\
\hline
\end{tabular}

cepat 2 jam 48 menit dan paling lama EGDT adalah 5 jam 30 menit (Tabel 7). Pengamatan terhadap hemodinamik tekanan darah dalam hal ini MAP selama dilakukan EGDT terdapat peningkatan MAP yang bermakna dengan 3 pasien yang dilakukan EGDT diberikan support norepinefrin untuk meningkatkan MAP.

Resusitasi cairan yang diberikan berupa cairan kristaloid serta koloid, juga terdapat 7 orang pasien yang diberikan produk darah baik itu PRC dan juga FFP. Mayoritas pasien memberikan respons dengan peningkatan CVP selama enam jam selama dilakukan EGDT, begitu pula dengan hasil keluaran urin pada semua pasien terdapat peningkatan rata-rata yang bermakna tiap jam, menandakan perfusi ke organ ginjal dapat diperbaiki sehingga keluaran urin dapat membaik. ${ }^{5}$

Hasil kadar laktat rata-rata pada pasien sepsis berat yang dilakukan EGDT mengalami penurunan dengan hasil laktat $>1 \mathrm{mmol} / \mathrm{L}$ sebanyak 19 pasien, menandakan hipoksia global teratasi sehingga metabolisme anaerob tidak berlangsung lebih lanjut yang ditandai dengan penurunan kadar laktat. ${ }^{1}$ Kadar laktat menurun tetapi rata-rata masih di atas normal ( $>1 \mathrm{mmol} / \mathrm{L}$ ). Keadaan ini disebabkan oleh normalisasi kadar laktat membutuhkan waktu yang cukup lama dan lebih dari 6 jam. Peningkatan kadar laktat pada pasien sepsis berat disebabkan oleh beberapa faktor salah satunya ialah hipoperfusi jaringan akut yang mengakibatkan metabolisme anaerob serta menghasilkan laktat. Penyebab lainnya yang meningkatkan kadar laktat ialah sepsis yang mengganggu aktivitas enzim, yaitu piruvat dehidrogenase, peningkatan laktat melalui peningkatan katekolamin, dan juga penurunan klirens laktat karena disfungsi hati. ${ }^{7,10}$

Sebaliknya, pada hasil nilai $\mathrm{ScvO}_{2}$ rata-rata pada pasien sepsis berat yang dilakukan EGDT mengalami perbaikan, sebanyak 25 pasien dengan nilai $\mathrm{ScvO}_{2} \geq 70-80 \%$, terendah $72,2 \%$ dan tertinggi $82,1 \%$. Hasil ini menandakan kebutuhan oksigen pada jaringan terpenuhi sehingga hipoksia global telah dapat teratasi ditandai dengan nilai $\mathrm{ScvO}_{2}$ yang meningkat. Berbeda dengan laktat, $\mathrm{ScvO}_{2}$ merupakan satu-satunya parameter yang dapat menilai keseimbangan pengiriman dan konsumsi oksigen sistemik. . $^{7,11}$

Faktor yang memengaruhi pencapaian resusitasi EGDT, yaitu faktor medis dan juga nonmedis. Berdasar atas hasil penelitian ini, diperlukan standard operasional prosedure (SOP) yang telah disepakati bersama dalam pelaksanaan EGDT pasien sepsis berat yang akan menjalani pembedahan sehingga dengan menentukan diagnosis yang cepat dan juga terapi awal yang tepat dapat menurunkan angka morbiditas serta mortalitas di Rumah Sakit Dr. Hasan Sadikin Bandung. Resusitasi EGDT masih berhasil dilaksanakan terhadap pasien yang terlambat dilakukan pemasangan CVC tetapi kondisi pasien sepsis berat masih dapat membaik dengan pengawasan yang benar.

\section{Simpulan}

Tingkat keberhasilan resusitasi EGDT telah sukses dilaksanakan pada 27 pasien dengan sepsis berat yang datang ke Instalasi Gawat Darurat (IGD) Rumah Sakit Dr. Hasan Sadikin Bandung.

\section{Daftar Pustaka}

1. Rivers E, Nguyen B, Havstad S, Ressler J, Muzzin A, Knoblich B, dkk. Early goaldirected therapy in the treatment of severe sepsis and septic shock. N Engl J Med. 
2001;345(19):1368-76.

2. Dellinger RP, Levy MM, Rhodes A, Annane D, Gerlach H, Opal SM, dkk. Surviving sepsis campaign: international guideline for management of severe sepsis and septic shock. Crit Care Med. 2012;41:580-636.

3. Elixhauser A, Friedman B, Stranges E. Septicaemia in US hospital, 2009. HCUP Statistical Brief \#122. October 2011. Agency for Healthcare Research and Quality, Rockville, MD. [diunduh 19 September 2014]. Tersedia dari: http: //www.hcup-us.ahrg.gov/reports / statbriefs/sb122.pdf

4. Eissa D, Carton G, Buggy DJ. Anesthetic management of patients with severe sepsis. Br J Anaesth. 2010;105(6):734-43.

5. Daniels R. Surviving the first hours in sepsis: getting the basic right (an intensivist's perspective). J Antimicrob Chemother. 2011;66(Suppl 2):ii11-23.

6. Carney ED, Matsushima K, Frankel H.
Treatment of sepsis in the surgical intensive care unit. IMAJ. 2011;13:689-95.

7. Berger T, Green J, Horeczko T, Hagar Y, Garg N, Suarez A, dkk. Shock index and early recognition of sepsis in the emergency departement. Western J Emerg Med. 2013; 14(2):168-74.

8. Levinson AT, Casserly BP, Levy MM. Reducing mortality in severe sepsis and septic shock. Semin Resp Crit Care Med. 2011;32(2):195-205.

9. Ely W, Goyette R. Sepsis with acute organ dysfunction. Dalam: Hall J, Schmidt AG, Wood LH, penyunting. Principle of critical care. Edisi ke-3. New York: Mc Graw-Hill, Medical Pub Division; 2005. hlm. 699-734.

10. Derek C, Van der Poll A. Severe sepsis and septic shock. N Engl J Med. 2013;369(9): 840-51.

11. Soong J, Soni N. Sepsis: recognition and treatment. Clin Med (London, England). 2012;12(3):276-8. 